\title{
Monitoring of the vapourer moth (Orgyia antiqua Linnaeus, 1758)
}

\section{Monitoring lotu znamionówki starki (Orgyia antiqua Linnaeus, 1758)}

\author{
Barbara H. Łabanowska*, Zofia Płuciennik, Wojciech Piotrowski, Barbara Sobieszek
}

\section{Summary}

The vapourer moth (Orgyia antiqua L.) is a polyphagous pest occuring on many trees and bushes, including apple, currants and raspberry. In 2013 and 2014 monitoring of this pest using pheromone traps to attracting males was carried out in apple orchards at the Research Institute of Horticulture. Butterflies of the vapourer moth were caught on pheromone traps placed in all monitored orchards however: there was no damage to the leaves caused by caterpillars. Adult flight of $O$. antiqua usually began in the second half of June and ended in late of October or even early November. The second generation of butterflies was more numerous in monitored orchards than the first one. The main flight of males of the first generation took place in July and another in September. The vapourer moth population was not abundant in the monitored orchards and there was no need to control it.

Key words: vapourer moth; Orgyia antiqua; monitoring

\section{Streszczenie}

Znamionówka starka (Orgyia antiqua L.) jest polifagiem, który może występować na wielu drzewach i krzewach liściastych, w tym także na jabłoni, porzeczkach, malinie. W latach 2013-2014, w Instytucie Ogrodnictwa prowadzono monitoring tego szkodnika w sadach jabłoniowych z wykorzystaniem pułapek z feromonem do wabienia samców. We wszystkich monitorowanych sadach w pułapkach z feromonem odłowiono motyle znamionówki starki, ale nie stwierdzono uszkodzeń liści przez gąsienice. Wylot osobników dorosłych znamionówki starki rozpoczynał się zwykle w drugiej połowie czerwca, a kończył pod koniec października lub nawet w pierwszych dniach listopada. W większości sadów drugie pokolenie motyli było bardziej liczne niż pierwsze. Główny wylot motyli pierwszego pokolenia odbywał się w lipcu, a drugiego we wrześniu. W monitorowanych sadach liczebność populacji znamionówki starki była niewielka i nie było potrzeby jej zwalczania.

Słowa kluczowe: znamionówka starka; Orgyia antiqua; monitoring lotu

Instytut Ogrodnictwa

Zakład Ochrony Roślin Sadowniczych

Pracownia Entomologi

Konstytucji 3 Maja 1/3, 96-100 Skierniewice

*corresponding author: Barbara.Labanowska@inhort.pl 


\section{Wstęp / Introduction}

Znamionówka starka (Orgyia antiqua L.) (Lepidoptera) należy do rodziny brudnicowatych (Lymantridae) (Buszko i Nowacki 2000). Jest to gatunek wielożerny (polifagiczny), który może występować na wielu drzewach i krzewach liściastych, w tym także na jabłoni, porzeczkach, malinie (Stocki 2001; Alford 2007; Łabanowski i Soika 2012; Płuciennik i wsp. 2014). W latach 70-80. XX wieku znamionówka starka była jednym z kluczowych szkodników upraw sadowniczych (Dronka i wsp. 1976; Lipa i wsp. 1977). Powszechne stosowanie w sadach insektycydów o szerokim spektrum działania (środki fosforoorganiczne, syntetyczne pyretroidy) spowodowało jej wyniszczenie i przez wiele lat szkodnik ten nie był notowany w sadach. W ostatnich latach pojawiły się sygnały o ponownym występowaniu znamionówki starki w sadach, dlatego też w Instytucie Ogrodnictwa przeprowadzono monitoring tego szkodnika.

Celem badań było określenie dynamiki lotu motyli na podstawie odłowu samców w pułapki z feromonem oraz ocena występowania gąsienic w sadach.

\section{Materiały i metody / Materials and methods}

Badania prowadzono w latach 2013-2014. W 2013 roku monitoring prowadzono w 6 sadach jabłoniowych zlokalizowanych w województwie łódzkim: Dąbrowice (Sad Doświadczalny Instytutu Ogrodnictwa), w prywatnych sadach produkcyjnych w miejscowościach: Kamień, Tarczyn, Celinów i Szczuki oraz w jednym sadzie w województwie śląskim - w Zawadzie. W 2014 roku monitoring prowadzono w sadzie doświadczalnym w Dąbrowicach oraz w sadzie prywatnym w miejscowości Szczuki. Do monitoringu wykorzystano pułapki $\mathrm{z}$ feromonami do wabienia samców. Zastosowano dyspensery z feromonem znamionówki starki pochodzące z Holandii (Pherobank) oraz z Mołdawii (Biochemtech), które umieszczono w pułapkach lepowych typu delta (trójkątne). Pułapki zawieszano w sadzie, w koronie drzewa na wysokości około 1-1,5 m nad ziemią, w połowie czerwca i sprawdzano na obecność motyli dwa razy w tygodniu, aż do końca października/początku listopada. Każdorazowo liczono odłowione motyle i usuwano je z podłogi lepowej. Systematycznie, w miarę potrzeby (zabrudzenie, wyschnięcie kleju) wymieniano podłogi lepowe. Dyspensery z feromonem wymieniono jeden raz w sezonie (pod koniec lipca), po upływie około 5-6 tygodni od wywieszenia pułapek w sadzie. Zawartość związków wchodzących w skład feromonu jest opatentowana przez producenta.

W celu określenia liczebności gąsienic w każdym sadzie 2-krotnie w sezonie przeglądano po 10 pędów z 20 drzew (razem 200 pędów). Pierwszą lustrację wykonano po kwitnieniu jabłoni, a drugą w drugiej połowie lipca.

Uzyskane wyniki przedstawiono na rysunkach la-f, $2 \mathrm{a}, \mathrm{b}$ oraz w tabeli 1 .

\section{Wyniki i dyskusja / Results and discussion}

We wszystkich monitorowanych sadach w pułapki $\mathrm{z}$ feromonem odłowiono motyle znamionówki starki (rys. 3-4). Nie stwierdzono natomiast uszkodzeń liści przez gąsienice i nie obserwowano złóż jaj zimujących (rys. 5-6).

W 2013 roku, w sadzie Doświadczalnym w Dąbrowicach pierwsze osobniki znamionówki starki odłowiono w trzeciej dekadzie czerwca. Lot motyli pierwszego pokolenia trwał prawie do końca lipca, czyli przez okres 5 tygodni (rys. 1a). Maksimum lotu miało miejsce pod koniec pierwszej dekady lipca, kiedy odłowiło się 8 samców w ciągu tygodnia. Lot motyli drugiego pokolenia rozpoczął się w pierwszych dniach września i trwał do początku listopada. Między wylotem motyli pierwszego i drugiego pokolenia była przerwa w sierpniu. W sadach w miejscowości Tarczyn i Szczuki motyle znamionówki starki odławiały się od końca drugiej dekady czerwca do końca pierwszej dekady listopada (rys. 1c, e). Obydwa feromony odławiały podobną liczbę samców. W tych sadach drugie pokolenie było bardziej liczne niż pierwsze, a podczas najliczniejszych wylotów w październiku odławiano od 10 do 17 motyli w ciągu tygodnia. Nie notowano wyraźnej przerwy w odławianiu motyli pierwszego i drugiego pokolenia. W sadzie w Celinowie przebieg lotu motyli był bardzo zbliżony do tego w sadzie w Szczukach (rys. 1d, e). Najwięcej motyli odłowiono w październiku, około 10 sztuk w pułapkę $\mathrm{w}$ ciągu tygodnia. W sadzie w miejscowości Kamień okres lotu był krótki, motyle notowano tylko w pułapkach $\mathrm{z}$ feromonem holenderskim, w okresie od trzeciej dekady czerwca do początku sierpnia, a maksimum lotu miało miejsce na początku lipca, kiedy odłowiło się 8 motyli w pułapkę w ciągu tygodnia (rys. 1b). W miejscowości Zawada motyle odławiały się od końca czerwca do połowy sierpnia, ale nawet podczas maksimum lotu - w drugiej połowie lipca - odławiano niewielką ich liczbę, 4-5 osobników w ciągu tygodnia (rys. 1f).

W 2014 roku, w sadzie w Dąbrowicach motyle odławiały się od końca czerwca do początku trzeciej dekady października (rys. 2a), zaś w sadzie w miejscowości Szczuki od trzeciej dekady maja prawie do końca października (rys. 2b), z około 5-tygodniową przerwą w drugiej połowie lipca i pierwszej połowie sierpnia. W Dąbrowicach zastosowany był feromon holenderski, a w Szczukach feromon mołdawski. W obu sadach więcej motyli odławiało się $\mathrm{w}$ okresie lotu drugiego pokolenia szkodnika, a maksymalne odłowy były na poziomie 8-10 motyli w pułapce w ciągu tygodnia.

Uzyskane dane wskazują, że wylot samców znamionówki starki rozpoczynał się zwykle w drugiej połowie czerwca (jedynie w sadzie w Szczukach w 2014 roku pod koniec maja), a kończył się pod koniec października lub nawet $\mathrm{w}$ pierwszych dniach listopada. W większości sadów drugie pokolenie było bardziej liczne niż pokolenie pierwsze (tab. 1). Średnio z 8 sadów udział odłowionych motyli pierwszego pokolenia wynosił $28,7 \%$, a pokolenie drugie stanowiło 71,3\%. Główny wylot motyli pierwszego pokolenia odbywał się w lipcu, a drugiego we wrześniu. Pułapki z obydwoma typami feromonów (holenderskim i mołdawskim) monitorowały podobny przebieg lotu motyli szkodnika (rys. 1, 2). Obecność motyli znamionówki starki stwierdzono we wszystkich sadach, w których zawieszone były pułapki $\mathrm{z}$ feromonem, jednak liczba odławianych samców nie była zbyt wysoka. W okresach maksymalnych 
a)

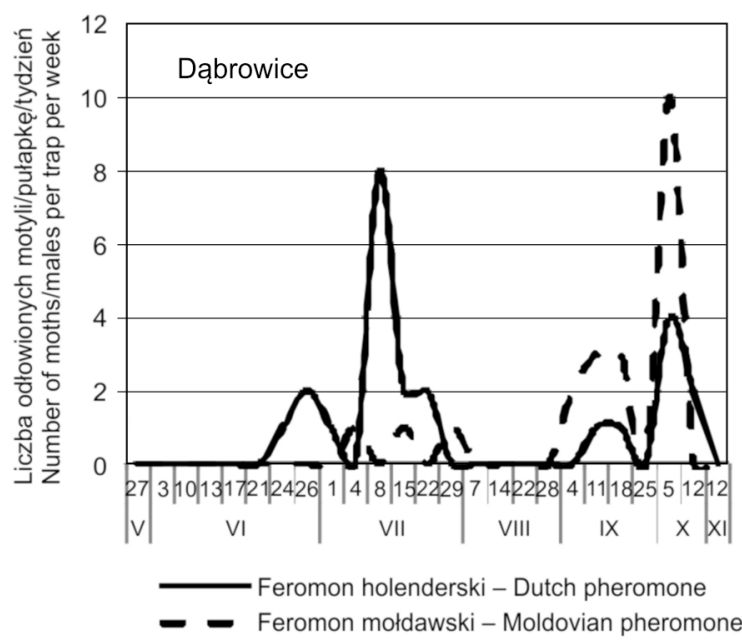

c)
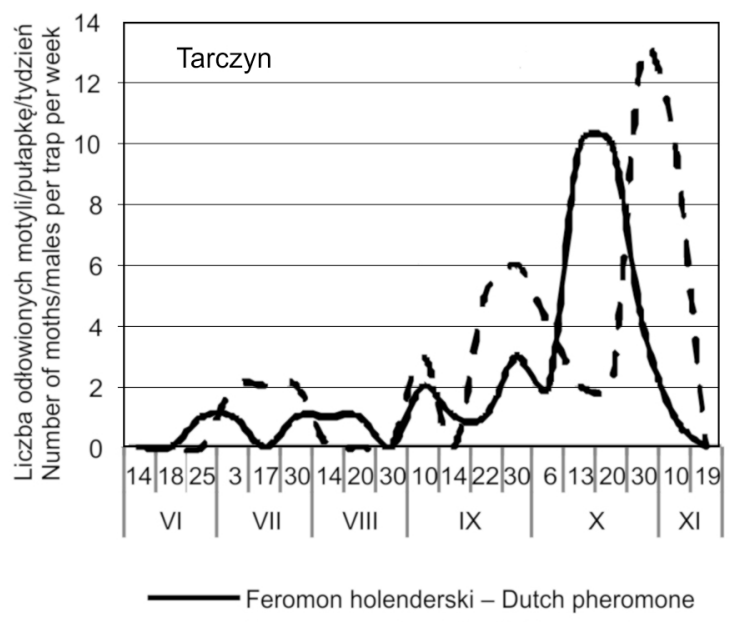

- Feromon mołdawski - Moldovian pheromone

e)



b)

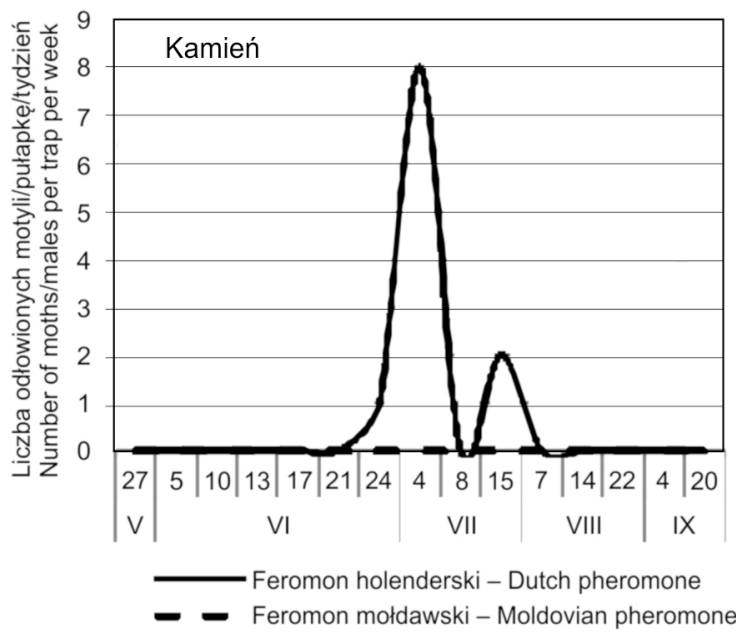

d)



- Feromon holenderski - Dutch pheromone

- Feromon mołdawski - Moldovian pheromone

f)



- Feromon holenderski - Dutch pheromone

- Feromon mołdawski - Moldovian pheromone

Rys. 1. Dynamika lotu motyli znamionówki starki (Orgyia antiqua) w 2013 roku

Fig. 1. Flight dynamics of the vapourer moth (Orgyia antiqua) in 2013 
a)

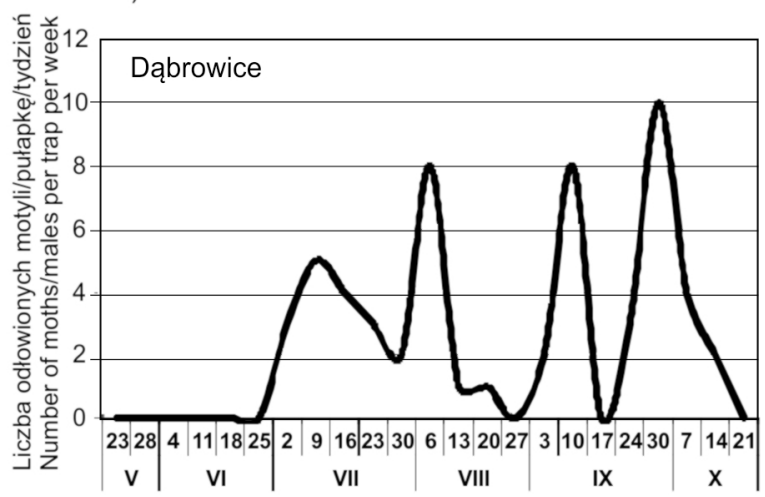

b)

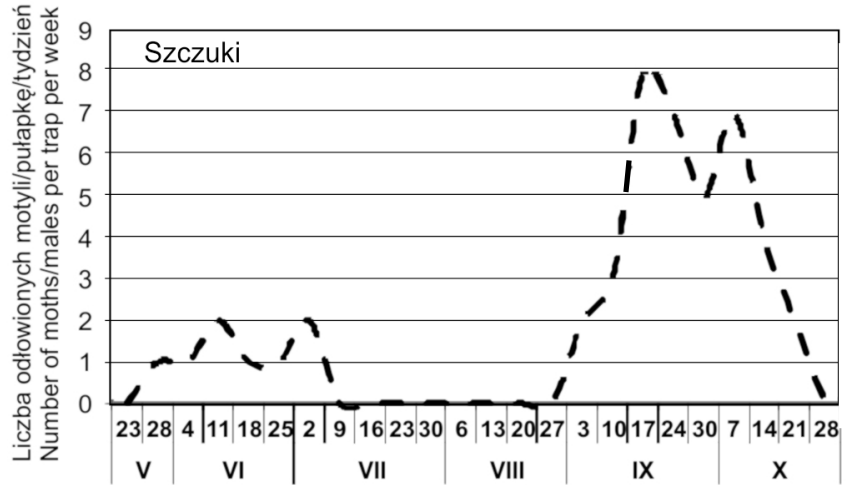

Rys. 2. Dynamika lotu motyli znamionówki starki (Orgyia antiqua) w 2014 roku

Fig. 2. Flight dynamics of the vapourer moth (Orgyia antiqua) in 2014

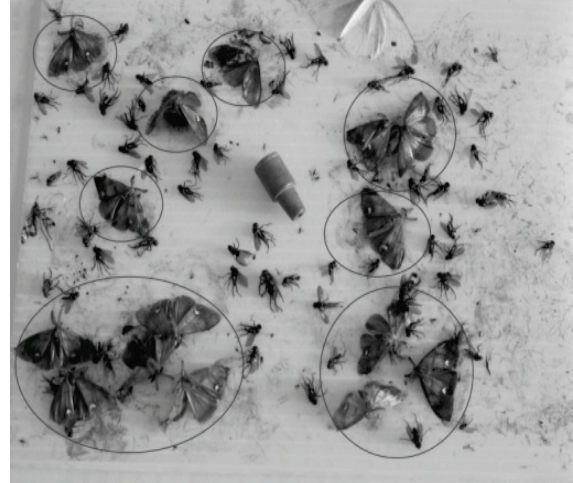

Rys. 3. Motyle (ठ̂) znamionówki starki

Fig. 3. Butterflies (ठ) of Orgyia antiqua (fot. - photo by W. Piotrowski)

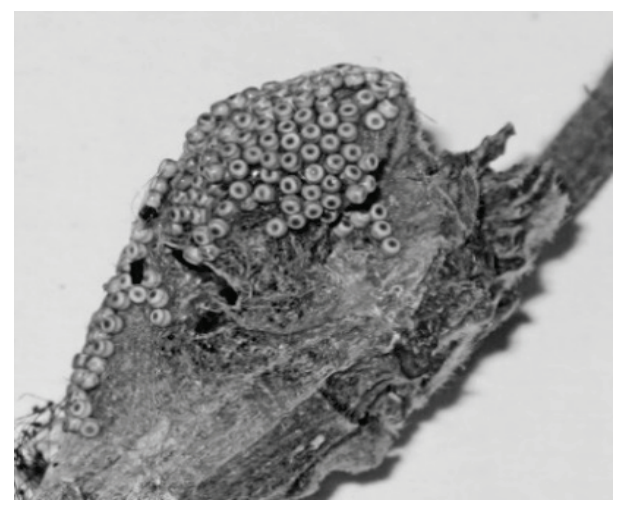

Rys. 5. Złoże jaj zimujących

Fig. 5. Wintering eggs

(fot. - photo by G. Łabanowski)

wylotów notowano 14-16 motyli w pułapce w ciągu tygodnia.

W żadnym z sadów nie notowano uszkodzeń liści przez szkodnika, a gąsienice występowały sporadycznie. Obecność tylko pojedynczych gąsienic lub ich brak na liściach pomimo odłowów samców w pułapki w sadzie prawdopodobnie wynika z ich zniszczenia przy zwalczaniu innych szkodników, jak np. zwójkówek liściowych (Płuciennik i Olszak 2006). Nie można również wykluczyć, że

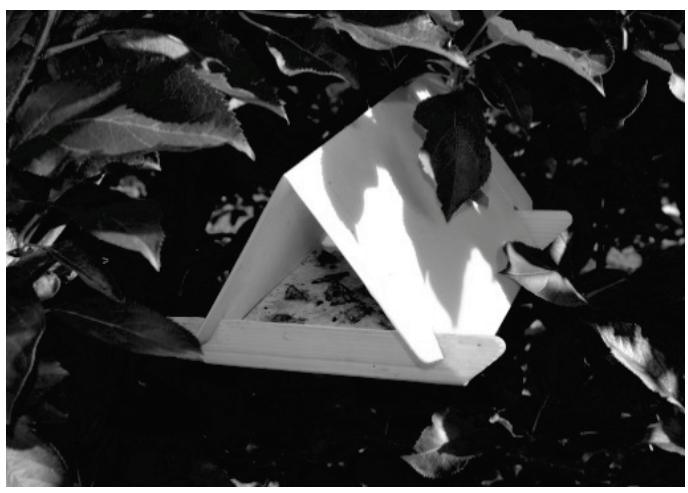

Rys. 4. Pułapka Delta z odłowionymi motylami znamionówki starki

Fig. 4. Delta trap with caught moths of Orgyia antiqua (fot. - photo by W. Piotrowski)

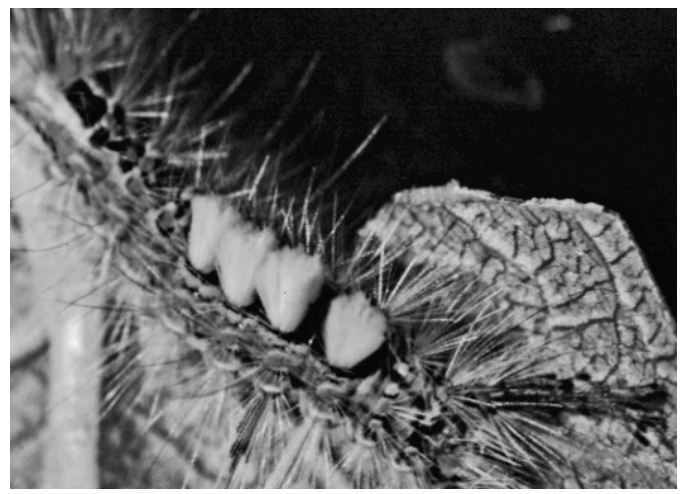

Rys. 6. Gąsienica znamionówki starki

Fig. 6. The caterpillar of Orgyia antiqua

(fot. - photo by G. Łabanowski)

pułapki z feromonami odławiały samce znamionówki starki z drzew rosnących w pobliżu sadów. Położenie sadu i jego otoczenie ma istotny wpływ na liczbę i strukturę odławianych do pułapek z feromonami gatunków motyli (Audemard i Daures 1992).

Obecność znamionówki starki stwierdzono w Polsce również na drzewach i krzewach ozdobnych (Łabanowski i wsp. 2000; Soika i Łabanowski 2015). 
Tabela 1. Odłowy motyli znamionówki starki (Orgyia antiqua) w pułapki z feromonem

Table 1. The catches butterflies of the vapourer moth (Orgyia antiqua) in pheromone traps

\begin{tabular}{|c|c|c|c|c|}
\hline \multirow{2}{*}{\multicolumn{2}{|c|}{$\begin{array}{l}\text { Lokalizacje i lata } \\
\text { Localizations and years }\end{array}$}} & \multicolumn{3}{|c|}{$\begin{array}{l}\text { Liczba motyli/samców/1 pułapkę z feromonem } \\
\text { Number of moths/males per } 1 \text { pheromone trap }\end{array}$} \\
\hline & & $\begin{array}{l}\text { ogółem } \\
\text { total }\end{array}$ & $\begin{array}{l}\text { I pokolenie } \\
\text { I generation }\end{array}$ & $\begin{array}{l}\text { II pokolenie } \\
\text { II generation }\end{array}$ \\
\hline \multicolumn{5}{|c|}{2013} \\
\hline Dąbrowice & $\begin{array}{l}\mathrm{M} \\
\mathrm{H}\end{array}$ & $\begin{array}{l}21 \\
24\end{array}$ & $\begin{array}{c}3 \\
16\end{array}$ & $\begin{array}{c}18 \\
8\end{array}$ \\
\hline Kamień & $\begin{array}{l}\mathrm{M} \\
\mathrm{H}\end{array}$ & $\begin{array}{c}0 \\
11\end{array}$ & $\begin{array}{c}0 \\
11\end{array}$ & $\begin{array}{l}0 \\
0\end{array}$ \\
\hline Szczuki I & $\begin{array}{l}\mathrm{M} \\
\mathrm{H}\end{array}$ & $\begin{array}{l}57 \\
63\end{array}$ & $\begin{array}{l}13 \\
11\end{array}$ & $\begin{array}{l}44 \\
52\end{array}$ \\
\hline Szczuki II & $\begin{array}{l}\mathrm{M} \\
\mathrm{H}\end{array}$ & $\begin{array}{l}51 \\
39\end{array}$ & $\begin{array}{l}6 \\
5\end{array}$ & $\begin{array}{l}45 \\
34\end{array}$ \\
\hline Celinów & $\begin{array}{l}\mathrm{M} \\
\mathrm{H}\end{array}$ & $\begin{array}{l}53 \\
37\end{array}$ & $\begin{array}{l}10 \\
10\end{array}$ & $\begin{array}{l}43 \\
27\end{array}$ \\
\hline Zawada & $\begin{array}{l}\mathrm{M} \\
\mathrm{H}\end{array}$ & $\begin{array}{l}7 \\
9\end{array}$ & $\begin{array}{l}7 \\
9\end{array}$ & $\begin{array}{l}0 \\
0\end{array}$ \\
\hline Ogółem -Total & & 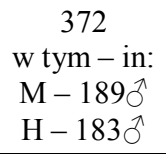 & 101 & 271 \\
\hline \multicolumn{5}{|c|}{2014} \\
\hline Dąbrowice & $\mathrm{H}$ & 56 & 27 & 29 \\
\hline Szczuki & $\mathrm{H}$ & 46 & 8 & 38 \\
\hline Ogółem - Total & & 102 & 35 & 67 \\
\hline
\end{tabular}

$\mathrm{M}$ - feromon mołdawski - moldovian pheromone, $\mathrm{H}$ - feromon holenderski - dutch pheromone

Zastosowane feromony holenderskie i mołdawskie odławiały porównywalną liczbę motyli i prawidłowo określały przebieg lotu. Ogółem w 6 obiektach w pułapki z dyspenserami z Mołdawii odłowiło się 189 osobników, a $\mathrm{W}$ pułapki $\mathrm{z}$ dyspenserami $\mathrm{z}$ Holandii odpowiednio 183 (tab. 1). Obraz przebiegu lotu motyli rejestrowany z wykorzystaniem dwóch różnych dyspenserów był również porównywalny.

Do monitoringu lotu motyli znamionówki starki mogą być wykorzystane pułapki $\mathrm{z}$ feromonem. Znajomość dynamiki lotu motyli może być pomocna przy określaniu terminów zwalczania, zwłaszcza w okresie lata. Metoda monitoringu poprzez odławianie samców motyli jest stosowana do określania terminów zwalczania innych ważnych gospodarczo szkodników w sadach (Płuciennik i Olszak 2006, 2008).

\section{Wnioski / Conclusions}

1. Znamionówka starka (O. antiqua) w Polsce rozwija dwa pokolenia.

2. Lot motyli pierwszego pokolenia ma miejsce pod koniec czerwca i w lipcu, zaś drugiej generacji we wrześniu i październiku.

3. Zastosowane feromony produkcji holenderskiej i mołdawskiej do odłowu samców znamionówki starki prawidłowo monitorowały dynamikę lotu motyli.

4. W monitorowanych sadach pomimo odławiania motyli w pułapki z feromonem, nie zachodziła potrzeba zwalczania znamionówki starki.

\section{Literatura / References}

Alford D.V. 2007. Pests of Fruit Crops. Manson Publishing Ltd.: 349-350.

Audemard H., Daures V. 1992. Trapping survey of populations of lepidopteran pests in 2 apple orchards for an integrated control programme. Acta Phytopathologica et Entomologica Hungarica 27: 1-4, 51-57.

Buszko J., Nowacki J. 2000. The Lepidoptera of Poland - a distributional checklist. Polish Entomological Monographs 1, 178 pp.

Dronka K., Niemczyk E., Olszak R. 1978. Skuteczność preparatu bakteryjnego Dipel i niektórych insektycydów w zwalczaniu znamionówki tarniówki (Orgyia antiqua L.) w sadach jabłoniowych. Roczniki Nauk Rolniczych, Seria E, 7 (1): 75-80. 
Lipa J.J., Bąkowski G., Rychlewska M. 1977. Skuteczność mikrobiologicznych insektycydów Bactospeine, Dipel, Selectzin i Thuricidae w zwalczaniu znamionówki tarniówki (Orgyia antiqua L.) (Lepidoptera, Lymantriidae) na jabłoniach. Prace Naukowe Instytutu Ochrony Roślin 19: 183-190.

Łabanowski G., Orlikowski L., Soika G., Wojdyła A. 2000. Ochrona ozdobnych krzewów liściastych. Plantpress, Kraków: 76-77, 181; 272 ss.

Łabanowski G., Soika G. 2012. Motyle (Lepidoptera) występujące na plantacjach róż (Rosa canina i $R$. rugosa) uprawianych metodą ekologiczną. Zeszyty Naukowe Instytutu Sadownictwa i Kwiaciarstwa im. Szczepana Pieniążka 20: 69-85.

Płuciennik Z., Łabanowska B.H., Piotrowski W., Gruchała M., Sobieszek B. 2014. Monitoring lotu znamionówki tarniówki (Orgyia antiqua) w sezonie 2013. 57. Ogólnopolska Konferencja Ochrony Roślin Sadowniczych „Integrowana ochrona roślin gwarancją owoców wysokiej jakości”. Ossa koło Białej Rawskiej, 11-12 lutego 2014: 141-142.

Płuciennik Z., Olszak R.W. 2006. Wykorzystanie pułapek feromonowych do monitoringu owocówki jabłkóweczki i zwójkówek liściowych w sadach. [An application of the pheromone traps to monitoring of codling moth and leaf roller populations in the orchards]. Progress in Plant Protection/Postępy w Ochronie Roślin 46 (2): 399-402.

Płuciennik Z., Olszak R.W. 2008. Monitoring zwójki koróweczki za pomoca pułapek feromonowych. Ogólnopolska Naukowa Konferencja Ochrony Roślin Sadowniczych Instytutu Sadownictwa i Kwiaciarstwa. Skierniewice, 12-13 marca 2008: $166-167$.

Soika G., Łabanowski G. 2015. Szkodniki ozdobnych krzewów liściastych i pnączy. Plantpress, Kraków: 44, 115, $121 ; 192$ ss.

Stocki J. 2001. Drzewa liściaste i owady na nich żerujące. Multico Oficyna Wydawnicza, Warszawa: 47; 256 ss. 